\title{
Research into practice: evaluation of Skills Hub content and implications for library staff development in the creation of video OERs
}

\author{
Jonas House, University of Sheffield \\ Georgina Dimmock, University of Northampton
}

\begin{abstract}
The University of Northampton Skills Hub is an online open-access repository of academic skills resources whose primary content is a body of short video open educational resources (OERs) created in-house by staff. To ensure OER quality and to identify staff development needs, the Skills Hub: Review, Redesign, Rebuild project was conducted. The project assessed the quality of fifty of the Skills Hub's video OERs by inviting fifteen reviewers from different user groups to critically assess the resources. The results were analysed thematically and then considered in relation to the extant literature on the creation of multimedia educational resources and online OERs. Four main practical categories required attention in the creation of future video OERs: technical, presentation, structural and content. These four categories fed into four superordinate categories regarding cognition and reception of OERs: comprehension, concentration, information retention and professionalism. Practitioner recommendations are made for video OER producers, and the findings are situated in relation the principles of multimedia learning theory.
\end{abstract}

Keywords: OERs; Skills hub; video; staff development; library; academic skills; multimedia learning; educational psychology

\section{Introduction}

In September 2013, Library and Learning Services (LLS) at the University of Northampton launched the Skills Hub (LLS, 2013), a repository of open educational resources (OERs) focussing on academic and information skills. At the point of launch the Skills Hub contained 70 open educational resources (OERs), 50 of which took the form of videos. Most of these videos had been created in-house by LLS staff. Six months after launch, the Skills Hub: Review, Redesign, Rebuild research project was carried out in order to evaluate the success of the OERs and to identify opportunities for improvement and staff training.

The background and development of the Skills Hub are briefly explained below, before the main body of the paper outlines the evaluative research project and highlights its main findings, which are presented as four key areas for attention in future video OER production.

The findings offer a contribution to the practitioner literature in the shape of a number of empirically supported recommendations for future video OER producers to ensure resource quality. Further, we suggest that institutions developing videos with a similar staff base may benefit from the practical conclusions resulting from the research. 
A contribution to the theoretical literature is also made as the empirical findings are shown to support many of the key principles of 'multimedia learning theory' within educational psychology (Mayer, 2009). The paper concludes with a summary of the key recommendations before returning briefly to a discussion of the implications of the findings for the Skills Hub, reflecting on how the user experience data can contribute to the process of developing an online resource repository in future. Opportunities for further research are also identified.

\section{Background}

Behind the development of the Skills Hub were dual motivations. The first was to provide online support to students, staff, and members of the local community who study or work off-site from the University. The second motivation was to build staff skill and confidence in producing teaching and learning materials in non-text dominant formats. This was in response to the Future Work Skills 2020 report from the University of Phoenix highlighting the need for 'new media literacies beyond text' (Davis et al., 2011, p.8) where employees have the 'ability to critically assess and develop content that uses new media forms, and to leverage these media for persuasive communication'.

\section{Skills Hub development}

In developing content for the Skills Hub, academic librarians and study skills tutors were asked by library management to identify those areas of academic skill requiring the most support and to focus on the development of video content to meet that need. Library management felt that staff were skilled in using text-based formats as a result of their habituated use of text editing and email programs, with the implication that staff were choosing to use text when other media formats might provide better support for students. To enable the staff to develop video content, rapid development teams (RDTs) were formed in the spring of 2013. The RDTs enabled staff to have protected time to experiment and to work in small groups to develop videos using film, screen capture software and simple animation tools. Their video content was uploaded to the Skills Hub and went live in September 2013. The Skills Hub is based on the WordPress blogging platform and allows users to comment upon content, rate it and share content using social media. The software also records usage data such as page visits, video play data and sharing via social media.

\section{Evaluation of Skills Hub resources}

Six months after the launch of the Skills Hub, an evaluative research project was conducted to assess the quality and effectiveness of the OERs and to identify trends that would enable library staff to improve future video content. This is in keeping with calls for OER producers to engage in the systematic evaluation and improvement of such resources (Huang, 2005) and to implement quality assurance procedures (Nikoi \& Armellini, 2012).

The remainder of this article explains the methodology of the research project and its main findings, presented as four key areas for attention. The findings are discussed in relation to the psychological literature on multimedia learning theory. The practical implications for designers of future OERs are discussed with an emphasis on staff development. 


\section{Methodology}

The Skills Hub: Review, Redesign, Rebuild study was designed to obtain unstructured qualitative assessments of the fifty skills videos on the project website. The research was an exploratory, inductive study. It sought to identify key themes in the reviewers' assessments of the videos, a body of data which could then be used as 1) a basis for development of future practice in the University, and 2) a contribution to the theoretical literature on the development of OERs and multimedia educational resources.

The research was designed to allow key themes to emerge from the data without being guided by theoretical principles from the outset. Once the analysis had been undertaken and the key themes in the data had been identified, the findings were contextualised in relation to theoretical and practitioner literatures. This research design was in accordance with established principles for undertaking qualitative investigation in the social sciences (Hood, 2005), in which the central thesis arises from the data, rather than prior to data collection.

Although the research was deliberately designed to have no prior theoretical suppositions, there were a number of general research questions that it sought to answer:

- What are the main themes in reviewers' assessment of the videos?

- Does the user profile (e.g. undergraduate, school-age, etc.) have a bearing on assessments of the videos? If so, how?

- What recommendations can be made for the improvement of future videos? Are these subsumable under a set of general principles?

- How do the findings contribute to the theoretical literature on the development of OERs and multimedia educational resources?

Fifty of the Skills Hub videos were selected to be assessed by the reviewers. The method of data collection was the Skills Hub: Review, Redesign, Rebuild blog (LLS, 2014) created specifically for the project. The videos were uploaded to the blog, and were split into ten 'blocks', each containing five videos. The blocks were used to roughly organise the videos according to which audiences they served (school pupils, undergraduates, international students and so on), usage level on the Skills Hub, and whether the topics were induction-level. Some blocks, such as the data analysis videos, were grouped thematically. The use of blocks helped to break up the videos to make the process more manageable for the reviewers. Reviewers were instructed to watch certain videos, and to leave a comment underneath each video providing a critical assessment of its positive and negative aspects. Reviewers were provided with a guidance sheet that outlined the general content and length of the posts that were expected from them.

The university-based reviewers (undergraduate, postgraduate and international students) were asked to watch all of the videos. The school-based reviewers (pupils and teachers) were asked to watch fourteen of the videos, which were grouped into a 'Schools' block for ease of reference. Reviewers were obtained through purposive sampling using contacts in university departments and schools. An initial intention to elicit demographic differences in user attitudes was not pursued due to the large degree of coherence in responses and the constraints on demographic comparison posed by a relatively small sample size. Consequently our analysis treats the 
respondents as a single group, although we would suggest that attributes of OERs which reportedly hindered viewer understanding are likely to have an exaggerated effect on international students' comprehension due to the extra challenges imposed by watching videos in a non-native language.

Efforts to ensure research 'dependability' (Gray, 2011, p.194) included provision of the dataset as an open-source research tool via the project blog (LLS, 2014), as well as the full research report on which this article is based (House, 2014). The validity of the study has potentially been aided by the authors' position within the research setting as 'practitioner-researchers' (Gray, 2011, p.416). No specific efforts at generalizability were made, although it is suggested that the strength of support for key themes and substantial thematic coherence - the 'force of example' (Flyvbjerg, 2004) - in the responses means that a degree of logical extrapolation of the findings is possible. Consequently we would recommend that future OER producers in other contexts consider our findings when seeking to optimise OER quality. Furthermore our findings closely support a body of existing theoretical literature, strongly implying their external applicability. This is an area that requires verification through further research.

\section{Results: Video OERs, multimedia learning theory, and practitioner recommendations}

Within the 350 reviewer comments that form the main body of data, eight key themes were identified. The first four of these are practical categories that arose directly from the data and which are key areas of attention for current and future producers of multimedia OERs. These are 1) technical problems, 2) presentation issues, 3) structural requirements and 4) information content. The latter four themes relate to cognition and reception and are 5) comprehension, 6) concentration, 7) information retention and 8) professionalism. It is these four superordinate categories that are used to organise the present article. Each is explained in turn, with evidence presented from the data and an explanation of how the evidence contributes to theoretical debates. Key practitioner recommendations are made at the conclusion of each of the four sections. It is argued that attention to the first four practical categories can ensure quality in the latter four superordinate categories, and further, that this finding is supported by material from multimedia learning theory. Readers seeking a more detailed exposition of the first four practical categories are directed to the final research report (House, 2014, p.11-30).

All themes arose from analysis of the data alone and were not developed alongside any theoretical material. When a detailed literature review was conducted after the analysis the present research was found to offer substantial support for the theory of multimedia learning. The chief proponent of this work is the educational psychologist Richard Mayer (2009) but the field has also been developed by a number of other researchers. Consequently, material from Mayer's definitive 'Multimedia Learning' (2009) is worked into the analysis alongside other salient research in the field.

Mayer's central thesis is that people learn better from multimedia sources - that is, by words and pictures than from words alone $(2009$, p.223) - but that there are a number of conditions which have to be met in order for enhanced learning to be facilitated. These conditions are articulated under twelve distinct 'principles for multimedia learning' (Mayer, 2009, p.267-268), which are 
summarised in Table 1. Many of these principles are supported by our data, which Table 2 summarises.

\begin{tabular}{|c|c|}
\hline Overall objective & Principles involved \\
\hline \multirow{5}{*}{$\begin{array}{l}\text { Reduction of } \\
\text { extraneous } \\
\text { processing }\end{array}$} & $\begin{array}{l}\text { 1. Coherence Principle: People learn better when extraneous words, } \\
\text { pictures and sounds are excluded rather than included }\end{array}$ \\
\hline & $\begin{array}{l}\text { 2. Signalling Principle: People learn better when cues that highlight the } \\
\text { organization of essential material are added }\end{array}$ \\
\hline & $\begin{array}{l}\text { 3. Redundancy Principle: People learn better from graphics and } \\
\text { narration than from graphics, narration and on-screen text }\end{array}$ \\
\hline & $\begin{array}{l}\text { 4. Spatial Contiguity Principle: People learn better when corresponding } \\
\text { words and pictures are presented near rather than far from each other } \\
\text { on the page or screen }\end{array}$ \\
\hline & $\begin{array}{l}\text { 5. Temporal Contiguity Principle: People learn better when } \\
\text { corresponding words are presented simultaneously rather than } \\
\text { successively. }\end{array}$ \\
\hline \multirow{3}{*}{$\begin{array}{l}\text { Management of } \\
\text { essential } \\
\text { processing }\end{array}$} & $\begin{array}{l}\text { 6. Segmenting Principle: People learn better when a multimedia lesson } \\
\text { is presented in user-paced segments rather than as a continuous unit. }\end{array}$ \\
\hline & $\begin{array}{l}\text { 7. Pre-training Principle: People learn better from a multimedia lesson } \\
\text { when they know the names and characteristics of the main concepts. }\end{array}$ \\
\hline & $\begin{array}{l}\text { 8. Modality Principle: People learn better from graphics and narration } \\
\text { than from animation and on-screen text. }\end{array}$ \\
\hline \multirow{4}{*}{$\begin{array}{l}\text { Fostering } \\
\text { generative } \\
\text { processing }\end{array}$} & $\begin{array}{l}\text { 9. Multimedia Principle: People learn better from words and pictures } \\
\text { than from words alone. }\end{array}$ \\
\hline & $\begin{array}{l}\text { 10. Personalization Principle: People learn better from multimedia } \\
\text { lessons when words are in conversational style rather than formal style. }\end{array}$ \\
\hline & $\begin{array}{l}\text { 11. Voice Principle: People learn better when the narration in } \\
\text { multimedia lessons is spoken in a friendly human voice rather than a } \\
\text { machine voice. }\end{array}$ \\
\hline & $\begin{array}{l}\text { 12. Image Principle: People do not necessarily learn better from a } \\
\text { multimedia lesson when the speaker's image is added to the screen. }\end{array}$ \\
\hline
\end{tabular}

Table 1: Overview of the twelve principles of effective multimedia design (adapted from Mayer, 2009, p.267-268. Used with permission of Cambridge University Press) 


\begin{tabular}{|c|c|c|}
\hline Theme & Contents of theme & $\begin{array}{c}\text { Relevant principles of } \\
\text { multimedia learning theory }\end{array}$ \\
\hline \multicolumn{3}{|l|}{ Practical categories } \\
\hline 1) Technical problems & $\begin{array}{l}\text { - audio problems } \\
\text { - video problems }\end{array}$ & $\begin{array}{l}\text { - No exact fit - possible } \\
\text { implications for Coherence } \\
\text { Principle }\end{array}$ \\
\hline 2) Presentation issues & $\begin{array}{l}\text { - background music } \\
\text { - spoken element } \\
\text { - visual element } \\
\text { - fit between spoken and visual } \\
\text { element } \\
\text { - overall pace }\end{array}$ & $\begin{array}{l}\text { - Coherence Principle } \\
\text { - Redundancy Principle } \\
\text { - Spatial Contiguity Principle } \\
\text { - Temporal Contiguity Principle } \\
\text { - Modality Principle } \\
\text { - Voice Principle }\end{array}$ \\
\hline $\begin{array}{l}\text { 3) Structural } \\
\text { requirements }\end{array}$ & $\begin{array}{l}\text { - introductions, summaries, re- } \\
\text { caps and conclusions needed } \\
\text { - steps / stages } \\
\text { - numbering of stages }\end{array}$ & $\begin{array}{l}\text { - Signalling Principle } \\
\text { - Segmenting Principle }\end{array}$ \\
\hline 4) Information content & $\begin{array}{l}\text { - 'less is more' } \\
\text { - key points } \\
\text { - clear, appropriate examples } \\
\text { - links to other material }\end{array}$ & $\begin{array}{l}\text { - Coherence Principle } \\
\text { - Signalling Principle }\end{array}$ \\
\hline \multicolumn{3}{|c|}{ Superordinate categories related to cognition and reception } \\
\hline 5) Comprehension & \multirow{4}{*}{$\begin{array}{l}\text { - technical problems } \\
\text { - presentation issues } \\
\text { - structural requirements } \\
\text { - information content }\end{array}$} & \multirow[t]{4}{*}{$\begin{array}{l}\text { Principles related to first four } \\
\text { themes all have a bearing on the } \\
\text { four superordinate categories. }\end{array}$} \\
\hline 6) Concentration & & \\
\hline $\begin{array}{l}\text { 7) Information } \\
\text { retention }\end{array}$ & & \\
\hline 8) Professionalism & & \\
\hline
\end{tabular}

Table 2: Outline of key research themes and their relevance to multimedia learning theory

One of the central findings of the present research is that multimedia learning theory is of particular relevance to producers of multimedia OERs who are seeking to ensure quality and viewer uptake. It is recommended that producers of multimedia OERs accommodate the central principles of multimedia learning theory, whether this is through individual study or by way of 
an institutional staff development programme which teaches the key principles. Evidence for how multimedia learning theory is related to practical considerations about video OER production is presented throughout the following four sections: comprehension, concentration, information retention, and professionalism.

\section{Comprehension}

The majority of videos received some feedback on their comprehensibility, whether this was because they were understandable and easy to follow or confusing. Positive responses were generally relatively vague in comparison to negative ones, a theme that pervaded the results. Some positive reviews did comment on specific points, which related either to presentation or structure.

Comprehension was aided by elements pertaining to presentation. These included the use of appropriate and explanatory visual aids, the pacing of the videos so that they were slow enough to understand, and the inclusion of animations and for additional support. Comprehension was also aided by elements pertaining to the structure of videos. This included the division of material into stages, each of which was clearly shown on-screen, the use of re-capping screens and the effective and coherent ordering of information. Praise for the use of stages reflects multimedia learning theory's 'segmenting principle', that people learn better when multimedia resources are presented in user-paced segments (Mayer, 2009, p.179-185; Mayer \& Chandler, 2001; Mayer et al., 2003a). Although the videos analysed here are not user-paced, the division of videos into stages may give users time to process information and aid their understanding of the structure of the material presented. This is certainly suggested by related work on the positive effects that the modular presentation of information engenders in other areas of educational task design (Gerjets et al., 2004).

The ways in which reviewers reported that the videos hindered comprehension fell into three of the four main practical categories: technical problems, presentation issues and information content. Technical problems that hindered comprehension were poor sound quality, fluctuations in volume, interference and background music. This finding supports previous research in multimedia learning theory and elsewhere, which indicates that extraneous sound or music hinders task completion and information retention (Kämpfe, et al., 2010; Moreno \& Mayer, 2000a), particularly when music is faster and louder (Thompson et al., 2012). Although Thompson et al. (2012) cite evidence that softer music has the potential to aid concentration, the present data indicate that music elicits a largely negative reaction, and should thus be avoided in the interests of creating resources appropriate for the largest range of viewers. Technical problems with the video track that hindered comprehension were poor video quality and pixelated images, which - in the same way as poor audio quality - directly inhibited viewers' ability to read and absorb key information.

Presentation issues that hindered comprehension were largely associated with a poorly presented spoken element. These factors included the speaker sounding bored, the content not being engaging, the speaker proceeding too fast and, where there was more than one speaker, an inconsistent speed and volume between speakers. These findings related to voice and speech serve to verify earlier work undertaken by multimedia learning theorists, which identifies voice 
characteristics in the narration of multimedia educational resources as salient to the effectiveness of learning (Atkinson, et al., 2005; Nass \& Brave, 2005; Mayer et al., 2003b).

Another important factor in this respect was the fit between spoken and visual elements. Twentytwo videos received over fifty comments for the lack of correlation between the audio and visual elements, which caused confusion and distraction. There were four main ways in which a poor fit was identified. In ten videos reviewers specified that there was a 'lag' between information being spoken and appearing on screen, or vice versa. On four occasions videos were criticised because information appeared in a completely different order on the audio track and the video track. Five videos received negative feedback because the visual element would hold on a particular screen for a long time, over which a large amount of spoken information was delivered. In three videos, information was mentioned in the audio track that did not appear on screen.

The importance of consistency between spoken and visual elements reflects two of Mayer's key principles of multimedia learning: the spatial contiguity principle, which holds that people learn better 'when corresponding words and pictures are presented near rather than far from each other on the page or screen' (Mayer, 2009, p.135; p.142-144; Moreno \& Mayer, 1999; Ginns, 2006), and the temporal contiguity principle, which holds that people learn better 'when corresponding words and pictures are presented simultaneously rather than successively' (Mayer, 2009, p.153, p.160-162; Mayer \& Anderson, 1992; Ginns, 2006).

Issues with the information content of videos that hindered comprehension included rushed sections, with information not sufficiently well explained. The need for additional detail or clarification was also highlighted. Emphasis of key words and other cues to indicate salient parts of video content, or 'signalling', has elsewhere been empirically demonstrated to improve learners' information transfer (Mautone \& Mayer, 2001). Multimedia learning theory's 'signalling principle' holds that people learn better from multimedia learning resources when signalling is used (Mayer, 2009, p.113).

The clear finding evident from the data is that attention to the four practical areas of technical issues, presentation, structure and content of videos, will aid the superordinate category of comprehension. Practitioners engaged in the creation of multimedia OERs are advised to attend to the areas identified above in order to enhance viewer comprehension of resources.

\section{Concentration}

A significant number of comments were made about the extent to which videos did or did not help concentration. Eight videos were praised because they contained elements that aided concentration and prevented viewers from becoming distracted. These elements were related to the theme of presentation. Videos were praised because their spoken element featured an engaging narrator. Videos also received positive feedback because their visual element involved the effective use of diagrams, animations, pictures and illustrations, bright colours, effects, and novel visual elements. These characteristics were all seen by reviewers as aiding concentration. Conversely, twenty videos were criticised because they contained elements that hindered concentration and distracted viewers. These elements were related to the themes of technical problems and presentation. Presentation issues that hindered concentration included dull or non- 
innovative visual formatting, in which there was a lack of colour and animation, or in which the presentation was simply perceived to be 'dull' or 'boring'. A crucial element of successful learning resources is not just that they aid comprehension and retention of information but also that they keep learners sufficiently motivated to pay attention. Once again this is a central issue to multimedia learning theory, which outlines principles for enhancing learner motivation (Mayer, 2009, p.221-262) that touch on similar points to the presentation issues identified by our reviewers. Most relevant here is the evidence that suggests that a friendly, conversational narrator aids learning more than an impersonal, robotic voice (Mayer, 2009, p. 249-251, 256257; Mayer \& Anderson, 1991; Mayer \& Anderson, 1992; Moreno \& Mayer, 2000b; Moreno \& Mayer, 2004), and that people learn better from a combination of words and pictures than from words alone (Mayer, 2009, p.233-235).

Reviewers also complained when presentations were perceived to be too close to a 'simple PowerPoint presentation', which was cited as affecting concentration. This point is supported by Mayer's (2009, p.119) work, which suggests that 'concise narrated animations' may be easier to learn from than videos in which points are reiterated on the spoken and visual channels. There was certainly an expectation from reviewers that the video OERs should be distinct from simple recordings of lecture-style PowerPoint presentations. Other visual elements were deemed to affect concentration were a lack of 'nice, concise' images, too much information presented on slides and over-complicated animations. These findings were concurrent with the coherence principle' of multimedia learning theory, which holds that 'people learn better when extraneous material is excluded' from multimedia learning resources (Mayer, 2009, p.89, p.95-98, p.101$105)$.

As with the responses around the theme of comprehension, a poor fit between audio and visual elements was noted by reviewers to affect their concentration. The principles for improving multimedia design discussed in relation to the above areas also hold for practitioner efforts to improve viewer concentration. Similarly, technical problems were also cited as negatively affecting concentration. These problems included poor sound quality, interference and echoing, and excessively loud background music.

\section{Information retention}

A similar theme to comprehension is that of retention of information by viewers, for which seventeen videos received comments. Both positive and negative comments provided detail about the aspects of the video that affected retention.

Six videos were praised for their content being easy to retain or remember. Three of these were due to memorable elements, e.g. 'the 3 Rs was my favourite part of the video as it was very catchy and stuck with me' and two were due to a clear and engaging speaker. One video was simply noted as being 'clear and easy to remember'. Although the evidence here is limited, these comments and others associated with the same videos appear to support the previous findings that attention to key practical areas tends to cause a more positive reception of videos. The positive reception of the ' 3 Rs' section - a bullet-pointed list of three things to remember suggests that these type of elements may be an effective means of enhancing viewer engagement with videos. 
Twelve videos were criticised for their content being difficult to retain or remember. These criticisms fell into the same four themes identified by the main analysis: technical problems, presentation issues, structural requirements and content. A technical problem reported as negatively affecting retention was a noise unintentionally left in at the end of one of the videos. Reviewers described this as irritating, and as hindering concentration and retention. Clearly practitioners need to ensure that any relatively easily rectifiable errors are addressed prior to releasing OERs. Although this example was directly connected to inhibited information retention by reviewers, the negative assessment of unwanted noises was a more general theme in the results, suggesting that their removal is important.

Presentation issues were also reported to inhibit retention. The spoken element of videos was criticised in this respect for being too fast and containing mistakes. The visual element of videos hindered retention as a result of 'uninspiring' presentation, recalling the above discussion of the importance of viewer engagement. Reviewers felt that more graphics would make the videos more interesting and engaging: for example, one reviewer identified the 'hand and speaker combination' as 'work[ing] best to help retain the information'. Multimedia learning theory identifies the combination of graphics and narration as an effective means of enhancing learning, although its 'redundancy principle' also supplies the caveat that inclusion of unnecessary elements can actually confound learning by engaging the learner in extraneous cognitive processing unrelated to the learning task (Kalyuga et al., 1998; Mayer, 2009, p.126-7). An appropriate balance of visual and audio elements must be sought in order to aid information retention and other aspects of learning, and we would suggest that this area indicates a key training need that could be aided by the application of insights from multimedia learning theory into OER practice.

The fit between spoken and visual elements was also a salient aspect of video presentation. A lack of information on the slides in certain presentations was noted, with a great deal of the spoken information not being transcribed on the slides. Again, the notions of spatial and temporal contiguity of information are shown to be relevant in enhancing learning, in this case by affecting retention as well as comprehension and concentration.

Inadequate amounts of content on certain videos was also identified as a negative aspect, with videos being criticised for containing too much information generally and needing to be broken down into separate parts. One reviewer suggested that the use of acronyms would help viewers to retain key material.

\section{Professionalism}

Professionalism was frequently invoked in positive appraisals of videos. Six videos attracted comments such as 'it is quite professional and interesting, engaging', 'I thought it look [sic] professional to say the least', 'had a professional feel, which is great'. The most positive comments were reserved for the only video analysed that was produced externally:

'The visual element is fantastic, along with the sound effects, and seems a lot more professional than a lot of the other videos on the Skills Hub'. 
Ten videos received negative comments specifically because of their lack of professionalism, which was associated with:

- Plainness or simplicity ('the video does not take advantage of the visual element, with only four slides in total, meaning that it did not feel professional')

- Poor technical skills ('fuzzy' or 'poor quality' audio, audible mouse-clicking, microphone being audibly switched off before the video ends, loud background music, unsuitable music, echoing voiceover, shaky filming)

- Poor presentation skills (pixelated images, stifled laughter and errors in the spoken element)

The literature on OER emphasises the importance of professionalism given the potentially global reach of internet-based skills resources. Nikoi and Armellini (2012, p178-9) argue that:

'the OER agenda has strong implications for institutional reputation and visibility...Institutions need to implement quality assurance processes at both [the design and development] levels to promote a positive image of the institution and engage with diverse OER user groups who can benefit from the resources and promote the institution where they were developed'.

This assertion is supported by one of the reviewer comments in the present research, which criticised a video on the grounds that it lacked the professional finish one might expect from a university'. As with the other themes explored above, professionalism clearly arises out of attention to more fundamental elements such as technical and presentation skills. It is recommended that practitioners focus on attaining as high a level of professionalism as possible, particularly given the global reach of OERs.

Of the four superordinate categories, professionalism had the least correspondence with multimedia learning theory. Nevertheless, our data suggest that high overall levels of professionalism correlate with greater acceptance of OER videos, and thus to an extent professionalism potentially aids the other three superordinate categories. It is possible that high levels of professionalism aid user engagement.

\section{Summary of findings}

The empirical findings of the study highlighted four practical areas that OER producers must focus on - technical, presentation, structural and information issues - in order to ensure OER quality. These were shown to contribute to four superordinate categories - comprehension, concentration, information retention, and professionalism - which are fundamental to the user experience of OERs, as summarised in Figure 1 below.

The data presented above demonstrates the applicability of multimedia learning theory to OER production, and we would suggest that prospective OER producers bear in mind these specific 
empirical examples, as well as the highly relevant but more general principles of multimedia learning theory, when creating OERs in future.

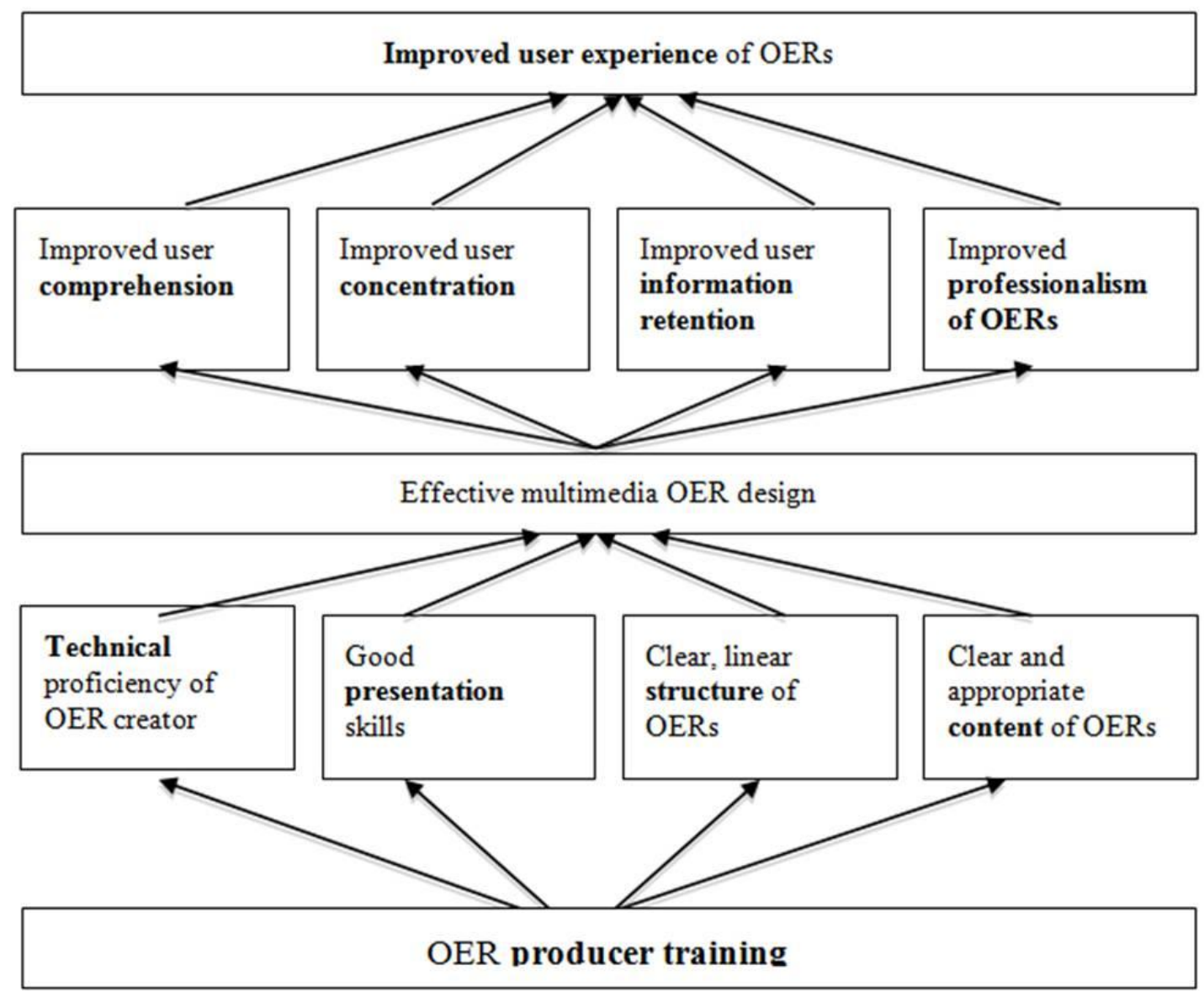

Figure 1: Relationship of practical areas of OER production to the superordinate categories

\section{Staff training recommendations}

The Library and Learning Services (LLS) staff who created the OER content on the Skills Hub were librarians and study skills tutors, rather than trained media specialists. Following consideration of how the user experience of video OERs could be positively affected by training interventions into OER creation, a set of staff development recommendations and guidance were made for the staff within LLS at the University of Northampton, outlined in Table 3 below.

We suggest that the identification of these training needs offers a basis for a provisional set of transferable, evidence-based recommendations for institutions or organisations seeking to develop OERs or OER repositories. Based on our evidence, our tentative proposals for other OER producers are also outlined in Table 3. One of the key recommendations is not to assume levels of competence within a body of staff: strengths and weaknesses vary considerably within 
any group, and it is worth devising a standard training programme in order to ensure a satisfactory level of adherence to the key principles of effective resource creation. Such a programme would incorporate the principles of multimedia learning.

\begin{tabular}{|c|c|c|c|}
\hline Area & $\begin{array}{l}\text { Recommendation for } \\
\text { Skills Hub staff }\end{array}$ & $\begin{array}{c}\text { General } \\
\text { recommendations }\end{array}$ & $\begin{array}{c}\text { Predicted user experience } \\
\text { outcomes }\end{array}$ \\
\hline $\begin{array}{l}\text { Presentation } \\
\text { skills }\end{array}$ & $\begin{array}{l}\text { Staff training needs: } \\
\text { - } \quad \text { spoken and } \\
\text { narrated element of } \\
\text { videos } \\
\text { - } \quad \text { skills to be an } \\
\text { engaging presenter }\end{array}$ & $\begin{array}{l}\text { Ensure staff are } \\
\text { trained on } \\
\text { presentation skills } \\
\text { prior to OER creation }\end{array}$ & \multirow{4}{*}{$\begin{array}{l}\text { 1) Viewer engagement will } \\
\text { be improved, leading to: } \\
\text { - better comprehension of } \\
\text { videos } \\
\text { - better retention of video } \\
\text { content } \\
\text { 2) Higher levels of } \\
\text { professionalism will be } \\
\text { achieved. This will: } \\
\text { - aid viewer engagement } \\
\text { - impact positively on the } \\
\text { university's institutional } \\
\text { reputation }\end{array}$} \\
\hline OER design & $\begin{array}{l}\text { Staff training needs: } \\
\text { - } \quad \text { appropriate } \\
\text { information content } \\
\text { of videos } \\
\text { - clear and linear } \\
\text { structure of videos }\end{array}$ & $\begin{array}{l}\text { Ensure staff are } \\
\text { trained on how to } \\
\text { structure their OERs, } \\
\text { and what information } \\
\text { to include }\end{array}$ & \\
\hline $\begin{array}{l}\text { Technical } \\
\text { proficiency }\end{array}$ & $\begin{array}{l}\text { Staff training needs: } \\
\text { - } \quad \text { procedures to } \\
\text { ensure audio quality } \\
\text { - } \quad \text { procedures to } \\
\text { ensure video quality }\end{array}$ & $\begin{array}{l}\text { Ensure staff are } \\
\text { trained to use OER } \\
\text { creation equipment } \\
\text { properly }\end{array}$ & \\
\hline Equipment & $\begin{array}{l}\text { Investment in } \\
\text { equipment: } \\
\text { - technical problems } \\
\text { were not always the } \\
\text { result of insufficient } \\
\text { training: sometimes } \\
\text { it appeared low } \\
\text { quality equipment } \\
\text { was the cause } \\
\text { - standardisation of } \\
\text { equipment will } \\
\text { improve quality } \\
\text { consistency }\end{array}$ & $\begin{array}{l}\text { Ensure the institution } \\
\text { has equipment of } \\
\text { sufficient quality prior } \\
\text { to OER creation } \\
\text { Ensure all OER } \\
\text { producers can access } \\
\text { equipment } \\
\text { Consider standardising } \\
\text { equipment used for } \\
\text { OER production to } \\
\text { improve consistency }\end{array}$ & \\
\hline
\end{tabular}

Table 3: Recommendations for OER producers and predicted user experience outcomes

\section{Implications for future development of Skills hub}

The videos evaluated for the Skills Hub: Review, Redesign, Rebuild study represent the first attempts by staff at moving from text into a video environment. The reviewers' comments provide an anonymised open-source dataset that these staff can use to inform the redesign of existing videos and the design of future ones. The reviewers' comments also demonstrate the 
need for staff development with regard to the four practical themes (technical proficiency, presentation, structure and content) and training on how those practical elements impact students' cognition and reception of the OERs with regard to the four superordinate categories (comprehension, concentration, information retention and professionalism).

In developing content for the Skills Hub it was known that staff would not possess all the necessary technical skills and that an element of the development would involve experimentation and learning. However, it was assumed that staff would possess sufficient skills in the areas of presentation, structure and content. The findings have shown that this was not the case and that in moving from text into the medium of video, specific staff development is required.

Rather than focussing on training staff, one option available would be to devolve all technical elements of video OER production to specialist multimedia professionals or filmmakers. However, this has implications for cost and the speed with which a video OER can be provided to the end user. In the same way that written, text based support can be generated the same day, a similar capacity via video could be seen as practical and desirable. Similarly, trained graphic artists and animators could be brought in to provide greater professionalism to visual aspects. Again, there are cost implications and these staff may not have the pedagogic skills to produce effective learning graphics. With regard to presentation and voiceovers, actors could be brought in to tackle these aspects, but again, there are cost implications and the use of actors may have an impact on the sense of authenticity and how the video OERs are received by students. Issues around authenticity and reception could form a future research study.

Following the Skills Hub: Review, Redesign, Rebuild project, management staff within LLS intend to continue capacity building within the current staffing body to meet future skills needs (Davis et al., 2011) and to increase the confidence of staff in producing OER content in non-text dominant formats. However, for multimedia OER content with a wide student reach i.e. across multiple subjects and educational levels, greater financial investment may be warranted and a collaborative approach is recommended, involving academic librarians, study skills tutors and professional filmmakers.

\section{Opportunities for future research}

Although the present study indicates that improvements in viewer comprehension, retention and viewer engagement will be achieved by attention to staff development in the four practical categories, further research is needed in this area. Our research is based on self-reported attitudinal data, and has not empirically tested the cognitive aspects of comprehension, retention and engagement. We suggest that future studies could build on our findings by undertaking such research, enabling a fuller exposition of the link between the issues identified in the present study and the existing body of work on the educational psychology of multimedia learning resources.

\section{References}

Atkinson, R. K., Mayer, R. E., and Merrill, M. M. (2005) 'Fostering Social Agency in Multimedia Learning: Examining the Impact of an Animated Agent's Voice'. Contemporary 
Educational Psychology, 30: 117-139. http://dx.doi.org/10.1016/j.cedpsych.2004.07.001

Davies, A., Fidler, D., Gorbis, M. (2011) Future Work Skills 2020. Institute for the Future, for the University of Phoenix Research Institute. Available at http://www.urv.cat/media/upload/arxius/CAE/oprofessional/future_work_skills_2020.pdf (accessed 12/7/14)

Flyvbjerg, B. (2004) Five Misunderstandings about Case-Study Research. In: C. Seale, G. Gobo, J. F. Gubrium and D. Silverman (eds) Qualitative Research Practice. London: Sage. http://dx.doi.org/10.4135/9781848608191.d33

Gerjets, P., Scheiter, K., and Catrambone, R. (2004) 'Designing Examples to Reduce Intrinsic Cognitive Load: Molar versus Modular Presentation of Solution Procedures'. Instructional Science, 32 (1-2): 33-58. http://dx.doi.org/10.1023/B:TRUC.0000021809.10236.71

Ginns, P. (2006) 'Integrating Information: A Meta-Analysis of Spatial Contiguity and Temporal Contiguity Effects'. Learning and Instruction, 16 (6): 511-525.

http://dx.doi.org/10.1016/j.learninstruc.2006.10.001

Gray, D. E. (2011) Doing Research in the Real World. Second edition. London: Sage.

Hood, J. (2005) Orthodoxy vs. Power: The Defining Traits of Grounded Theory. In: A. Bryant and K. Charmaz (eds) The SAGE Handbook of Grounded Theory. London: Sage.

House, J. (2014) Skills Hub: Review. Redesign, Rebuild Research Report. LLS, University of Northampton. Available at https://skillsinnovation.files.wordpress.com/2014/06/skills-hubreport.pdf (accessed 12/7/14).

Huang, C. (2005) 'Designing High-Quality Interactive Multimedia Learning Modules'. Computerized Medical Imaging and Graphics, 29 (2-3): 223-233. http://dx.doi.org/10.1016/j.compmedimag.2004.09.017

Kämpfe, J., Sedlmeier, P., and Renkewitz, F. (2010) 'The Impact of Background Music on Adult Listeners: A Meta-Analysis'. Psychology of Music, 39 (4): 424-448.

http://dx.doi.org/10.1177/0305735610376261

Kalyuga, S., Chandler, P., and Sweller, J. (1998) 'Levels of Expertise and Instructional Design'. Human Factors, 40 (1): 1-17. http://dx.doi.org/10.1518/001872098779480587

LLS (2013) Skills Hub. LLS, University of Northampton. Available at http://skillshub.northampton.ac.uk (accessed 12/7/14).

LLS (2014) Skills Hub: Review, Redesign, Rebuild. LLS, University of Northampton. Available at http://skillsinnovation.wordpress.com (accessed 12/7/14) 
Mautone, P. D, and Mayer, R. E. (2001) 'Signaling as a Cognitive Guide in Multimedia Learning'. Journal of Educational Psychology, 93 (2):.377-389.

http://dx.doi.org/10.1037/0022-0663.93.2.377

Mayer, R. E. (2009) Multimedia Learning. Cambridge: Cambridge University Press. http://dx.doi.org/10.1017/CBO9780511811678

Mayer, R. E., and Anderson, R. B. (1991) 'Animations Need Narrations: An Experimental Test of a Dual-Coding Hypothesis'. Journal of Educational Psychology, 83 (4): 484-490. http://dx.doi.org/10.1037/0022-0663.83.4.484

Mayer, R. E., and Anderson, R. B. (1992) 'The Instructive Animation: Helping Students Build Connections Between Words and Pictures in Multimedia Learning'. Journal of Educational Psychology, 84 (4): 444-452. http://dx.doi.org/10.1037/0022-0663.84.4.444

Mayer, R. E., and Chandler, P. (2001) 'When Learning is Just a Click Away: Does Simple User Interaction Foster Deeper Understanding of Multimedia Messages'. Journal of Educational Psychology, 93 (2): 390-397. http://dx.doi.org/10.1037/0022-0663.93.2.390

Mayer, R. E., Dow, G. T., and Mayer, S. (2003a) 'Multimedia Learning in an Interactive SelfExplaining Environment: What Works in the Design of Agent-Based Microworlds?' Journal of Educational Psychology, 95 (4): 806-813. http://dx.doi.org/10.1037/0022-0663.95.4.806

Mayer, R. E., Sobko, K., and Mautone, P. D. (2003b) 'Social Cues in Multimedia Learning: Role of Speaker's Voice'. Journal of Educational Psychology, 95: 419-425.

http://dx.doi.org/10.1037/0022-0663.95.2.419

Moreno, R., and Mayer, R. E. (1999) 'Cognitive Principles of Multimedia Learning: The Role of Modality and Contiguity'. Journal of Educational Psychology, 91 (2): 358-368. http://dx.doi.org/10.1037/0022-0663.91.2.358

Moreno, R., and Mayer, R. E. (2000a) 'A Coherence Effect in Multimedia Learning: The Case for Minimizing Irrelevant Sounds in the Design of Multimedia Instructional Messages'. Journal of Educational Psychology, 92 (1): 117-125. http://dx.doi.org/10.1037/0022-0663.92.1.117

Moreno, R., and Mayer, R. E. (2000b) 'Engaging Students in Active Learning: The Case for Personalized Multimedia Messages'. Journal of Educational Psychology, 92 (4): 724-733. http://dx.doi.org/10.1037/0022-0663.92.4.724

Moreno, R., and Mayer, R. E. (2004) 'Personalized Messages that Promote Science Learning in Virtual Environments'. Journal of Educational Psychology, 96 (1): 165-173. http://dx.doi.org/10.1037/0022-0663.96.1.165

Nass, C., and Brave, S. (2005) Wired for Speech: How Voice Activates and Advances the Human-Computer Relationship. Cambridge, Massachusetts: MIT Press. 
Nikoi, S., and Armellini, A. (2012) 'The OER Mix in Higher Education: Purpose, Process, Product, and Policy'. Distance Education, 33 (2): 165-184.

http://dx.doi.org/10.1080/01587919.2012.697439

Thompson, W. F., Schellenberg, E. G., and Letnic, A. K. (2012) 'Fast and Loud Background Music Disrupts Reading Comprehension'. Psychology of Music, 40 (6): 700-708.

http://dx.doi.org/10.1177/0305735611400173

\section{About the authors}

Jonas House worked as Research Assistant on the Skills Hub: Review, Redesign, Rebuild project and undertook the content analysis of the project data. He is now at the University of Sheffield.

Email: jhouse1@ sheffield.ac.uk

Georgina Dimmock led on the development of the Skills Hub and established the Skills Hub: Review, Redesign, Rebuild project. She is Head of Academic Liaison in Library and Learning Services at The University of Northampton.

Email: georgina.dimmock@northampton.ac.uk 